\title{
Integrating Usability into the Agile Development Process: A preliminary empirical study
}

\author{
Daniel A. Magües \\ Universidad Autónoma de Madrid, \\ Escuela Politécnica Superior, \\ Madrid, Spain, \\ daniel.magues@estudiante.uam.es \\ and \\ John W. Castro \\ Universidad de Atacama, \\ Departamento de Ingeniería Informática y \\ Ciencias de la Computación, \\ Copiapó, Chile, \\ john.castro@uda.cl \\ and \\ Silvia T. Acuña \\ Universidad Autónoma de Madrid, \\ Escuela Politécnica Superior, \\ Madrid, Spain, \\ silvia.acunna@uam.es
}

\begin{abstract}
Background: Interest in the integration of the agile software development process (ASDP) and user-centred design (UCD) has grown over the last decade. However, there are not many papers that study this issue holistically and uncover the current state of this integration. Aim: This study sets out to answer the following research question: What is the current state of integration between agile processes and usability? Method: We conduct a systematic mapping study (SMS). We analyze the articles and the results were cross checked by the authors, and any disagreements were discussed and resolved in meetings. Results: We retrieved a total of 161 Primary Studies. There are very few papers that study the literature holistically and report the current state of usability in the ASDP. Conclusions: We categorized according to four criteria: process, practice, team and technology integration. The largest group refers to process integration with a total of 76 Primary Studies.
\end{abstract}

Keywords: Agile software development, user-centred design, systematic mapping study, usability.

\section{Introduction}

ASDP is an umbrella term for a set of methods and practices based on the values and principles expressed in the Agile Manifesto. Solutions evolve through collaboration between self-organizing, cross-functional teams utilizing the appropriate practices for their context [1]. UCD is an approach to user interface design focusing on how it will be understood and used by a human user throughout the planning, design, and development stages of a product [2]. Judging by the increase in the number of publications over the last decade, the integration between ASDP (like XP [3], SCRUM [4]) and UCD has been the focus of research over the last 
few years $[5][6][7][8]$. There are three possible reasons for this growing interest. First, UCD is useful for understanding the needs of potential system users and how software can support user goals and activities and improve system usability and the satisfaction of users interacting with the system. However, the ASDP does not usually take into account such features [6][8]. Usability is a quality attribute of software system use and relies not only on the appearance of the user interface but also on how the user interacts with the system. Second, none of the major ASDPs, like SCRUM, include guidelines on how to develop usable software. Additionally, the user interface designer and usability engineer role either does not exist or is not clearly defined in agile teams [7][9]. Third, ASDP and UCD appear to differ as to their principles and philosophies (for example, a focus on customers versus end users, working versus usable software, unit testing versus usability testing). This raises challenges for attempts at achieving integration [10][7].

ASDPs are founded on the Agile Manifesto, which gives precedence to values like the capability to generate working software in short development cycles, the potential to respond to change and customer collaboration in contract negotiation [1]. The problem with this premise from the usability viewpoint is that it makes no mention of the importance of end-user collaboration throughout the software development process [11]. From the viewpoint of requirements engineering, for example, such constant collaboration causes requirements to emerge throughout the development process [12]. Agile processes recommend eliciting requirements as part of just-in-time evolutionary cycles as the software is built instead of them all being collected at the start of the project. According to some authors, this is a good strategy for handling and prioritizing "emerging requirements", (together with stakeholders) and adapting team workload accordingly [4][12]. On one hand, in the particular case of SCRUM, the requirements are accommodated in a product backlog as user stories. These user stories are living entities because they are constantly changing [4]. On the other hand, UCD places the user at the centre of the requirements analysis, design and evaluation activities in order to improve the usability of the final product [6]. UCD professionals apply UCD techniques and methods as part of a collaborative and iterative process [9][13]. Therefore, UCD professionals and teams enacting ASDPs are potentially compatible, and this would improve the user experience.

However, the usability requirements elicitation principles and practices applied in agile processes have been found to be wanting [7]. This occurs when, for example, the usability requirements are elicited in situ from customers that have a perfect understanding of the needs of system but not of the different types of end users. This is an obstacle to the identification of any usability problems that novice end users may have [14][15]. One of the principles of UCD, on the other hand, is to understand all the user profiles [15]. Human-computer interaction (HCI) is a discipline concerned with the design, evaluation and implementation of interactive computing systems for human use and with the study of major phenomena surrounding them [16]. Many authors working in the HCI domain claim that UCD professionals have to couple up their mindset with the agile process [4][17][18][19]. But this coupling is far from straightforward for two reasons. First, many UCD professionals work as part of teams that are separate from and provide support to the agile development team. Therefore, they have a different culture. Second, many professionals have had to develop their own strategies to align UCD practices with the ASDPs adopted by their organization [20]. Thus, the adaptation of usability techniques and methods is based on the experience of UCD professionals, and many such usability techniques require time and resources that an agile process cannot afford. Additionally, agile processes do not provide any guidelines for such adaptations.

Note that this research focuses on the adoption of HCI techniques in the ASDP. There are two reasons for adopting HCI techniques. Firstly, ASDP adoption as part of the organizational culture is considered to be a complicated process [4] and potentially even tougher if the agile team has to reenact that process. Secondly, there are several ASDPs (Scrum [21], XP [3] and Lean [22]) that are mature enough to assure, if implemented, return on investment for the organization [23]. However, more applications in real scenarios of proposals integrating HCI and ASDP should be conducted in order to confirm the results reported so far [24][25][26][27][28][29][30]. Additionally, we have identified two factors that make it more practicable to adopt HCI techniques in the ASDP . Firstly, no changes have to be made to the ASDP enacted by the team; the ASDP merely has to be adopt the activities proposed by the technique to achieve a UCD process and add value to the team and the process [31][32]. Secondly, the learning curve required for technique adoption is short, considering that the technique can be applied rapidly, at low cost, in any development stage [33] or with HCI expert participation in development teams [34].

Therefore, the first issue is to identify the current state of usability in agile processes in order to determine how to go about such an adaptation. The aim of this paper is precisely to explore the existing literature in order to ascertain this state. To achieve this aim, we conduct a systematic mapping study (SMS). A SMS is a form of systematic literature review that aims to identify and classify the research papers published about a specified issue [35]. 
This article is structured as follows. Section 2 describes the background and related work. Section 3 describes the research method, analysing how the literature is grouped and identifying knowledge gaps. Section 4 reports the types of usability and ASDP integration. Section 5 discusses the results. Section 6 describes the validity threats. Finally, Section 7 outlines the conclusions and future work.

\section{Related Work}

From our pilot search, we found that there were only four [15][36][7][5] systematic reviews related to our research question. The first literature review by Sohaib and Khan [15] does not detail the literature retrieval process. It is therefore potentially incomplete. From the literature that they did analyse, however, they draw similarities and differences between ASDPs and usability engineering, as result of which they propose joint strategies. For example, this review suggests combining the general approach of agile teams with specialists in usability. Agile teams are ideally broad spectrum, that is, they have a wide range of skills instead of a defined specialization, whereas usability engineering requires usability specialists. Therefore, they suggest forming a multidisciplinary team including non-specialists and specialists. Besides, they consider that, with a more iterative approach and performing usability testing throughout the project, usability engineering can be adapted to ASDPs. Although these strategies are designed to cover several integration issues, no details are given about how to apply these strategies in ASDPs.

The second paper by Da Silva et al. [36] reports a systematic literature review on the integration of ASDP and UCD. This literature review identified 58 Primary Studies for analysis and focuses on the usability problems encountered in agile projects (for example, having big design up-front is not an option regarding agile methods) and strategies for solving these problems. Da Silva et al. [36] identified strategies proposing the use of usability techniques (for example, prototyping) or making changes to the process including a sprint zero for preliminary design tasks. Nevertheless, they do not specify how these strategies have been applied. Finally, they suggest a process based on the strategies analysed in the literature. In view of the growth in the number of publications reported here, it is considered to be a very old (August 2010) and potentially incomplete review.

The third paper by Salah et al. [7] describes the systematic review conducted on the integration of ASDP and UCD. This review covers publications from 2000 to 2012 and reports 71 Primary Studies. The literature analysis manages to identify the challenges to ASDP and UCD integration and how to successfully deal with these challenges. The identified challenges include the the fact that time for UCD activities is short at the start of the project, UCD activities are hard to prioritize or UCD tasks are troublesome to divide up. Although they suggest strategies for overcoming these challenges, they do not detail how they can be applied.

Finally, Brhel et al. [5] conduct a review of the literature on the current state of ASDP and UCD integration and propose the general principles that constitute a user-centred agile process (UCASDP). This review analysed 83 publications and identified UCASDP principles, such as the separation of product discovery from product creation, iterative and incremental design and development and continuous participation. These principles were inferred by classifying the papers into four dimensions in order to determine the ASDP and UCD integration levels: process integration, practice integration, team integration and technology integration. The principles analysed by Brhel et al. [5] help to determine the conditions that a user-centred ASDP should meet. However, the effort required by the proposal by Brhel et al. [5] is sizeable because it requires changing the activities of an ASPD. We consider that this is something that ASDPs can not afford, and it is more practicable to apply techniques in order to improve usability within ASDP.

We have identified closely related works such as Fernandez et al. [37] and Ormenio and Panach [38]. Although these work are related to methods of evaluating the usability and elicitation of usability requirements, they do not mention integration with ASDP.

After analysing these papers reporting literature reviews aimed at identifying problems, challenges or principles for the integration of ASDPs and UCD, we find that the SMS reported in this paper differs from the above reviews in that it aims to identify existing research in the literature containing proposals for adopting a set of usability techniques for the purpose of formalized and systematic ASDP and UCD integration. None of the reviews in the literature address this issue. Therefore, it is necessary to investigate usability techniques that can be incorporated into the PDSA. 


\section{Research Method}

We conducted a systematic mapping study (SMS) [35] in response to the general research question: What is the current state of the integration of agile processes and usability? This general question is broken up into three specific questions:

- What kind of integration between ASDP and UCD are being made?

- What type of integration is the most popular?

- What is the least expensive type of integration to implement taking into account the characteristics of the agile community?

A SMS is a research method concerned with researching the literature in a particular field of interest and generating an overview in order to identify gaps that require further evaluation or validation [35].

\subsection{Databases and Search Protocol}

We started our mapping study by identifying keywords and some search strings that we inferred from the research question. We then ran a pilot search. This search returned some papers that were checked and rounded out by two expert software engineering researchers. This search was conducted to determine the best search strings. Table 1 illustrates the search string used in SMS. We used different synonyms to extend the scope of the search. The term "integration" is not included as a keyword as it may exclude relevant papers as we found during the pilot search.

Table 1: Keywords used for the search string

\begin{tabular}{|c|c|c|}
\hline \multicolumn{3}{|c|}{ Keywords } \\
\hline "usability" OR & & "agile development" OR \\
\hline "usability method" OR & & "agile software development" OR \\
\hline "usability technique" OR & & "agile method" OR \\
\hline "usability engineering" OR & & "agile process" OR \\
\hline "usability practice" OR & AND & "agile project" OR \\
\hline "user centered design" OR & & "agile practice" OR \\
\hline "user-centered design" OR & & "extreme programming" OR \\
\hline "user interaction" OR & & "scrum" \\
\hline "user experience" & & \\
\hline
\end{tabular}

This paper is a preliminary approximation to the literature because we initially used three electronic databases (DB) in the mapping study to get faster results: Scopus, ACM Digital Library and IEEE Xplorer. Table 2 reports the search fields used for each DB. We did not always use the same fields, as this depends on the options offered by each DB. The searches were conducted in the following order: Scopus, ACM Digital Library and IEEE Xplorer.

Table 2: Search strings by DB

\begin{tabular}{cc}
\hline BBDD & Campos de Búsqueda \\
\hline Scopus & "Title OR Abstract OR Keywords" \\
ACM Digital Library & "Abstract OR Title" \\
IEEE Xplorer & "Title OR Abstract OR Index Terms" \\
\hline
\end{tabular}

The search was ordered according to the DBs that returned most results. The search fields were selected to assure that searches were similar across DBs. The review covers papers published up until 15 October 2015. The inclusion and exclusion criteria established with respect to the title, abstract and keywords in order to retrieve the Primary Studies were as follows.

Inclusion criteria:

- The paper is written in English; AND

- The abstract or title mentions an issue regarding the integration of agile processes and usability; OR

- The abstract or title mentions an issue related to the integration of agile processes and UCD; AND 
- The abstract mentions an issue related to usability engineering or HCI techniques; OR

- The abstract mentions an issue related to the user-centred design process.

Exclusion criteria:

- The paper does not present any issue related to the integration of agile processes and usability; OR

- The paper does not present any issue related to the integration of agile processes and UCD processes.

\subsection{Paper Selection}

The first author ran the searches using the search strings and fields defined for each DB (Table 2). The set of papers returned by the search were called Retrieved Papers. The first author inspected the title, keywords and abstract to screen the retrieved papers. Any papers that looked like they might contain information about the integration of usability or UCD processes in agile developments were added to the group of Candidate Papers. The complete group of Candidate Papers was screened for duplicates. The resulting group was called Non-Duplicate Candidate Papers.

Note that when duplicates were retrieved, the first occurrence of the paper was retained and the others were deleted. Thus, as duplicates were removed from each of the DBs, the number of papers dropped. Accordingly, if the search order were changed, then the number of Non-Duplicate Papers retrieved from each DB might be different. A paper is considered to be a duplicate when several DBs return exactly the same paper. Of course, there could be several versions of the same paper (full paper and short paper), but we did not come across this case.

The first author read the abstract, introduction and conclusions of each of the papers belonging to the Non-Duplicate Candidate Papers group in order to determine whether they described any sort of integration between agile processes and usability for the purposes of classification. The results were cross checked by the second and third authors, and any disagreements were discussed and resolved in meetings. Finally, the new group output using these papers was called Primary Studies. In this preliminary approximation, we decided not to use either snowballing or reverse snowballing. This will be applied in the second round of this research. The Primary Studies that we identified included books, proceedings and journal articles. Table 3 summarizes the number of papers taken from each of the above groups. Note that the Scopus DB provides more selected papers. The references to the Primary Studies from this research are available at: https://sites.google.com/site/usabilitysms/home.

Table 3: Total number of papers retrieved frm each DB

\begin{tabular}{lcccc}
\hline \multicolumn{1}{c}{ DB } & Retrieved & Candidates & $\begin{array}{c}\text { Non-Duplicate } \\
\text { Candidates }\end{array}$ & $\begin{array}{c}\text { Primary } \\
\text { Studies }\end{array}$ \\
\hline Scopus & 257 & 153 & 153 & 142 \\
ACM Digital Library & 61 & 30 & 10 & 10 \\
IEEE Xplorer & 91 & 37 & 9 & 9 \\
TOTAL & $\mathbf{4 0 9}$ & $\mathbf{2 2 0}$ & $\mathbf{1 7 2}$ & $\mathbf{1 6 1}$ \\
\hline
\end{tabular}

Figure 1 shows the different research methods used in the Primary Studies. Case studies, grounded theory and observation are the most commonly used research methods.

Figure 2 provides an overview of the Primary Studies retrieved by the SMS. Figure 2 is basically composed of two scatter (XY) charts with bubbles at the intersections of each category (left-hand side). The categories are determined by primary study year, type (conferences, journal and book) and classification according to the focus area (team, practices, processes and technology) [5]. The size of each bubble is determined by the number of Primary Studies that have been classified as belonging to the respective categories at the bubble coordinates. The right-hand side of Figure 2 shows the number of Primary Studies by publication year.

From Figure 2, it is clear that, although the integration of ASDP and UCD has been on the agenda for over a decade, the number of publications started to grow as of 2007, and a lot of articles have been published each year since then. Therefore, although the idea of integrating ASDP and UCD has been around for some time, there are open questions regarding this integration such as, for example, the tight ASDP schedules that are an obstacle to the user testing sessions prescribed by UCD [39]. Note that there was an upturn in the number of publications in 2014, confirming the interest in this field. 


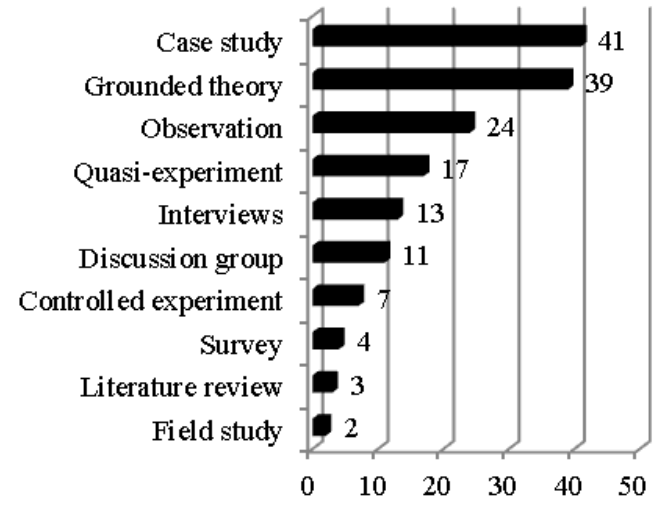

Figure 1: Articles by research method

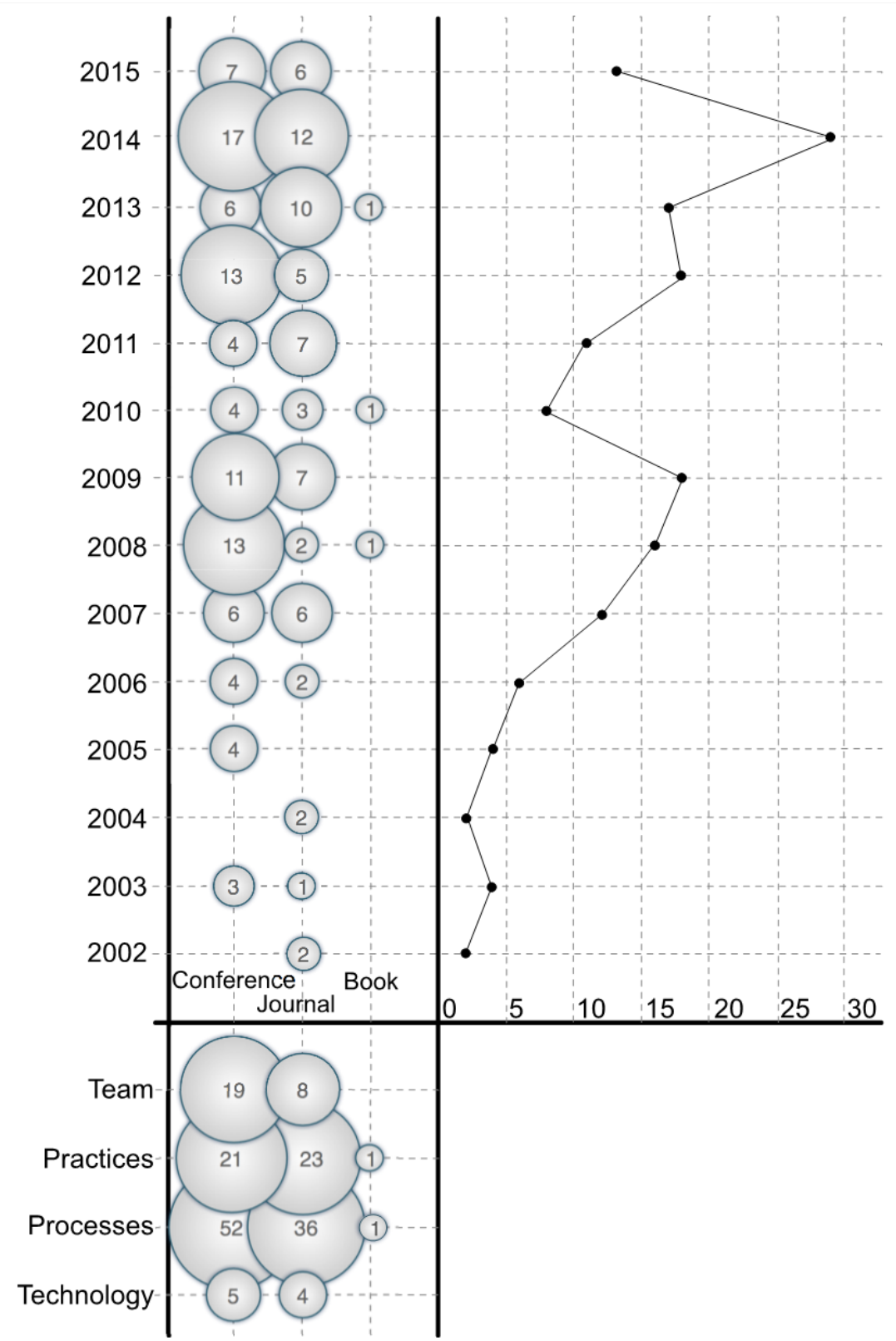

Figure 2: Mapping with the distribution of Primary Studies by focus area, including publication type and year 


\section{Synthesis of the results}

After conducting the SMS and analysing the literature with respect to the adoption of usability in the ASDP, we identified Primary Studies dealing with integration from four different perspectives: processes, practices, team and technology. Process integration is useful for coordinating activities for combining ASDP and UCD processes. Practice integration is useful for integrating practices and/or techniques into different ASDP stages and vice versa. Technology integration facilitates the integration of ASDP and UCD with the support of technological tools; and team integration identifies the human factor during the integration of these disciplines, is useful for defining team roles and structure in order to improve collaboration and communication in multifunctional teams with professionals from both disciplines (ASDP and UCD).

Figure 3 shows a Venn diagram summarizing the results of the classification of the 161 Primary Studies. This classification is based on the proposal by Brhel et al. [5]. However, Brhel et al. [5] identify 83 Primary Studies (with an October 2012 cut-off date), whereas our more recent (October 2015) SMS retrieves almost double the number of Primary Studies (a total of 161). This difference matches up with the publication peaks that occurred in 2013 and 2014 (see right-hand side of Figure 2).

In the following, we detail first each of the above four classification criteria. Then, we explain the three categories resulting from the "intersections" between the four identified categories giving examples of Primary Studies that represent these intersections.

\subsection{Process Integration}

Process integration has to identify how the activities involved in the software development process are organized at a more abstract level. Process integration means combining and synchronizing the UCD and ASDP processes, generating a unified process that includes both perspectives. This is the largest group of papers within the Primary Studies. The research methods used by the authors of the Primary Studies within this group include literature reviews [7][15], case studies [20][40][41][42][43][44][45][46][47][48][49], surveys of the opinion and lessons learned by ASDP and UCD practitioners [50][10][51][52][53][54][55] and grounded theory studies [56][57][58]. The results reported by the authors are generalizations of ASDP and UCD activities (for example, usability patterns to facilitate the use of the best agile usability practices) that can be combined in a single integrated model.

Worthy of note is the analysis by Constantine and Lockwood [59] of a flexible and model-based approach for designing web applications. They report good results for user interface and usability design with processes that have tight schedules like ASDP. The proposals of other authors are based on the observation of developments with a highly complex user experience. For example, Kieffer et al. [42] examine the need to combine UCD and ASDP for the development of an easy-to-use and easy-to-learn user interface to assure the satisfaction of adult users with the interface. Additionally, Øvad [55] explores the opportunities for integrating user experience design processes and methods and ASDP, particularly for the development of medical devices, and Wilkes [60] puts the accent on the Big Data era and the popularity of ASDP to propose changes in UCD in order to create more useful and easy-to-use tools for handling data.

Additionally, there are papers that apply specified, new or custom processes including ASDP and UCD activities that are validated in real projects or case studies. Processes like CRUISER [30], Enhanced Agile Process (EAP) [61], FlexREQ [62], Hybrid User Centered Development Methodology (HUCDM) [63][27], InterMod [64][65], Lean UX [29], Little Design Up-Front [24], Software Process Improvement Framework (SPI) [66], User-Centered Agile Software Development (UCASD) [5], Usability Maturity Model-Human Centredness Scale (UMM-HCS) [67], U-Scrum [68], eXtreme Scenario-based Design (XSBD) [11][69], Extreme Usability [70] and AGILEUX [71] have been identified. 


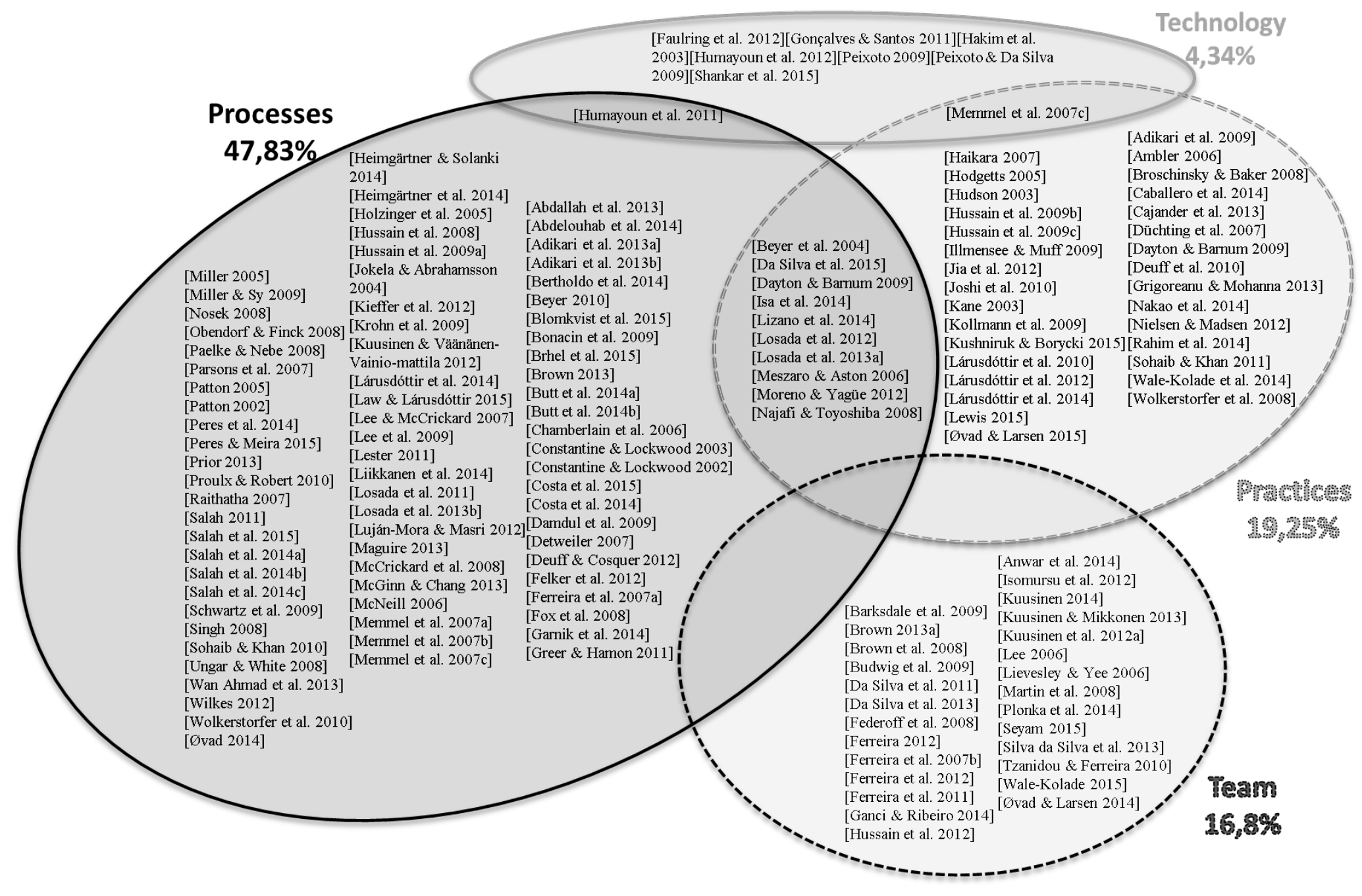

Figure 3: Classification of publications by integration type 
A noteworthy example is the paper by Adikari et al. [61] who describe the Enhanced Agile Process (EAP) and conduct a study comparing the design and development of a product with a team using EAP and another team using the current agile process. They report that the product built by the team using EAP is more focused on user experience design. Costa et al. [27] present the Hybrid User Centered Development Methodology which they describe as a simple, iterative and incremental process built upon the principles of UCD [72]. This process was implemented to develop a small-scale educational system and for a medium-sized business system, resulting in an international quality recognition for educational software. The eXtreme Scenario-based Design process is detailed by Lee et al. [11]. It is a compilation of joint research conducted by agile usability researchers and industry and concludes with four requirements to be met for effectively integrating ASDP and UCD: (i) appropriate prioritization of the goals driving design decisions, (ii) equilibrium between design decisions reflecting both high- and low-level objectives, (iii) synchronization of development and usability activities, and (iv) incremental development of the user interface, maintaining a design that is consistent as a whole. The AGILEUX model, proposed by Peres et al. [71], details a process integrating ASDP and UCD for small enterprises and the model focuses on the first level of maturity where seeks to establish a standard process within an organization by defining agile practices, principles, techniques and artifacts of user experience.

\subsection{Practice Integration}

The integration of practices considers the adoption of specific techniques. The Primary Studies in this category identify the adoption of UCD techniques in the ASDP and vice versa. This is the second-most studied group in the literature. From the analysis of papers, we found that the integration of HCI practices and/or techniques are integrated as prescribed in HCI. The aim in any case is to include the human factor or the user perspective in different SE activities by means of HCI techniques. During the analysis of the publications, we look for any mention of at least one HCI technique adopted in ASDP that has been applied in one way or another. We identified cases in which the author aims to identify the most common techniques used in ASDP projects by means of surveys or interviews regarding different software development projects. In such papers, the most common techniques identified include: research of the context of use [73], low fidelity prototypes [32][74] and workshops [75].

We have found publications that use observation and case studies of projects and teams experimenting with the adoption of HCI techniques in ASDP [76][77][78]. User research has been a topic of interest in such publications. Contextual inquiry usability technique was considered by Rahim et al. [79], Isa et al. [80] and Hudson [73] in order to identify factors like cultural background, health concerns and religious inclinations that may influence the decision on whether or not to use a product within the researched user community. Kushniruk and Borycki [33] describe the application of their proposal called low-cost rapid usability testing that has been applied in the agile development of healthcare systems. Da Silva et al. [39] suggest evaluation by means of usability inspections of lightweight prototypes.

Additionally, other authors propose the adoption of HCI techniques by means of a theory grounded on data gathered from surveys and interviews of ASDP and UCD practitioners with experience in this type

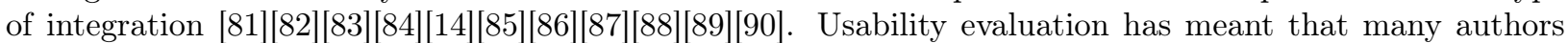
have had to design strategies that can be adopted within ASDP. According to the preliminary analysis by the authors, this was not straightforward because of the time constraints imposed by the agile development context. Dayton and Barnum [83] pinpoint the major obstacle to the adoption of usability testing in an agile process as being to plan and recruit a group of real users long enough in advance for the teams to be able to plan testing with users that are really representative of product customers. Lárusdóttir et al. [85] and the paper by Nielsen and Madsen [88] also report on the integration of usability testing. Additionally, from the analysis of this group, we identified the integration of other techniques such as cognitive walkthroughs [84], prototyping [65][87] and heuristic evaluation [8].

We have identified that some of the usability techniques are being adopted thanks to adaptations. For example, the HCI discipline establishes that all Contextual Inquiry participants (developers and users) must be previously trained and the team must necessarily participate in all multidisciplinary meetings in order to apply the technique [91]. However, agile development team members do not generally have background knowledge of usability technique application, and developers have limited time and work to a tight schedule. We have found that Beyer et al. [92] adapt Contextual Inquiry in two ways in order to solve these two problems. First, the user interface team compensates for the training gaps of the other participants. Second, due to agile development time constraints, developers are not involved until the end of the multidisciplinary meeting so as not to affect team work in the previous sprint. 


\subsection{Team Integration}

Team integration is construed as changes in the composition of teams to include experts from both HCI and SE disciplines (for example, adding a user experience designer to a developer team) and reflects the social interaction and knowledge creation among professionals of both disciplines.

The Primary Studies taht we have classified in this group, reveal an interest in a deeper understanding of the role of UCD professionals within a team applying ASDP [18][93][94][95][96][97][98][99][19][100][101][102][103]. Da Silva et al. [96] suggest that the role of the user experience designer in an agile environment is misunderstood. Lievesley and Yee [99] identify some key functions for the interaction designer working in an agile software development environment. Additionally, Kuusinen [102] proposes to divide the centralized user experience team and assign user experience specialists by business lines. These specialists would be assigned roles within the development teams, like product owner responsible decision making on the product.

Besides, we have identified papers that analyse the interaction between user experience teams and ADSP developers [93][104][105][106][107][108][109][110][111][17][112] with a view to integrating the work they do, considering social and cultural differences, geographical distribution or interorganizational collaboration. Ferreira et al. [105] suggest that having an interaction designer on the XP team leads to changes in the original XP process work flow. This affects the interaction among designers and developers. Working with Scrum teams particularly in large corporations, Budwig et al. [93] detail the practices of user experience teams. Blomkvist et al. [113] analyse one-to-one communication among UCD specialists believed to be a major factor for identifying users needs and design solutions in agile development.

We identified the three most common integration strategies in this category. First, User Experience (UX) teams implement agile methodologies [18]. At several stages of agile method adoption, team members express their fears, for example, about how to adapt usability testing to agile times, or what type of documentation and design should be generated taking into account that ASDP documentation is less formal. Second, the UX designer role is integrated into an agile environment, as proposed by several Primary Studies [96][105][97]. Third, the interaction of ASDP teams and UCD teams requires analysis to determine how teams with different cultures can coordinate activities and work together [114][104]. We have found that the strategy of including a new designer role within an agile team has met with acceptance [19][100][94][99]. We suppose that this strategy is interesting because it requires less investment in resources by the organization.

\subsection{Technology Integration}

Technology integration involves using technological media to support and coordinate activities enabling such integration. Examples of this integration were set by Humayoun et al. [115], who created the TaMUlator tool for use within an integrated development environment or IDE (in this case, Eclipse). TaMUlator is capable of automating the usability evaluations, using a task modelling language called TaMoGolog. Hakim et al. [116] propose the "Sprint" tool for small teams, used to define specifications and design and to help bring designers into synch with customers, analysts and developers about design decisions. The "Sprint" tool uses Shockwave or Flash prototypes to link project artefacts like personas, scenarios, screen designs, storyboards, requirements and use cases to design interactive specifications with these artefacts. Shakar et al. [117] consider that user testing in the laboratory is a bottleneck for user experience teams in an ASDP environment. As a result, they propose CogTool. CogTool is a tool capable of modelling user performance during testing. The resulting models can then be used to evaluate performance on new designs. Additionally, Peixoto and Da Silva [118] propose building an expert system that provides a design knowledge base for teams that use ASDP. This expert system is built on a semantic network representing the major HCI design concepts. Finally, Gonçalves and Santos [119] propose POLVO software for building low-fidelity prototypes to help to improve and increase the agility of ASDP interface prototyping.

\subsection{Process-Practice Integration}

This group includes the Primary Studies that propose integration by generating both a new process and adapting techniques at the same time. An example of this proposal is the paper by Beyer et al. [92], who propose the Rapid Contextual Design process. This process incorporates the customer voice and provides room for UI and user interaction design as part of the agile process. The process consists of 11 steps and it assumes a separate UI design team exists that will work out the details of the interface within the context of the User Stories. Some steps propose adaptations to several usability techniques, for example, contextual inquiry, and this is done in a cross-functional team of UI people, marketing, and developers. Additionally, 
Najafi and Toyoshiba [120] describes the Staggered Development Method in which the user experience team performs user research and testing, and designs for a specific feature one sprint ahead of engineering's implementation of the feature.

The paper by Da Silva et al. [39] proposes the execution of usability inspection evaluations on lightweight prototypes, taking advantage of the iterative nature of agile. As this iterative nature has not facilitated the execution of user testing sessions, Da Silva et al. propose a set of practices and improvements for specified artefacts at different stages of the ASDP in order to successfully evaluate the usability of a software product.

\subsection{Process-Technology Integration}

In this group, we have identified papers that propose a new process integrating ASDP and UCD and report technological tools that support process integration. We found only one case, reported by Humayoun et al. [6], who built a framework adopting UCD concepts in developments within ASDP. This framework defines the UCD activities that should be applied in different stages of the ASDP project life cycle: user involvement, design artefact evaluation, design improvement and detailed design evaluation by the user. Additionally, they developed the UEMan (User Evaluation Manager) and TaMUlator (Task Model-based Usability Evaluator) tools, which provide development environment-level integration for administering and automating a set of UCD activities. UEMan is a plug-in for the Eclipse development environment and is capable of administering and automating UCD activities for evaluation. It is useful for developers to integrate automated usability metrics as part of the project code. TaMUlator is a Java tool and provides a set of programming interfaces (APIs) for administering and automating usability evaluation based on a task model. TaMUlator provides an easy and dynamic mechanism for defining different usability scenarios for evaluation.

\subsection{Practice-Technology Integration}

The papers that propose the integration of techniques or practices with possible adaptations and the use of technological tools to assist with their adaptation fall into this intersection. We have identified one example of this integration. The paper by Memmel et al. [121] who explain their experience with iRise Studio. iRise Studio is a high-fidelity prototyping tool for application in agile development. This paper presents that collaborative design with stakeholders demands informal modelling methods that everybody can understand and apply. But using traditional, paper-based methods to gather and document requirements, an IT organization often experiences frustrating communication issues between the business and development teams. Therefore, the authors present ways of agile high-fidelity prototyping for corporate user interface design. Without harming agile principles and practice, detailed prototypes can be employed for collaborative design, can act as visual specifications and substitute paper-based artefacts.

\section{Discussion}

Our analysis reveals that practice and process integration is strongly represented in the sample. Whereas process integration is represented by 76 publications ( $47.83 \%$ of the total), practice integration is the second largest group of Primary Studies, with a total of 31 publications, that is, $19.25 \%$ of all of the Primary Studies retrieved in our SMS (161). Even though there are a lot of papers discussing integration processes, this does not necessarily mean that there is a wide variety of specified, comprehensive and systematic integration proposals. Generally, it was hard to distinguish between the process and practice integration approaches because the authors often discuss their work as an integration proposal providing details of the use of specific methods and neglecting the developer viewpoint. The team integration category is composed of 27 Primary Studies (16.77\%), and the least representative category is supporting technology integration with only seven Primary Studies (4.34\%). Of the Primary Studies, $11.18 \%$ are positioned around the category intersections.

Even though there are more publications on process integration, our research interest focuses on proposing the integrating of HCI usability practices or techniques because they do not involve far-reaching changes to ASDPs. This makes the integration of usability techniques into ASDP more feasible as it does not require a major effort in terms of team training or additional investments.

Judging by the increase in the number of publications since 2007, the integration of HCI activities and techniques with agile processes is of notable interest. However, there is as yet no agreement on what would be a formalized and more systematic integration. Therefore, it is an open research problem that requires 
much more research effort. Even though the literature retrieved by our SMS contains integration proposals, none proposes generally applicable guidelines for the agile development community to follow.

\section{Validity Threats}

On one hand, the validity of the SMS reported in this paper is threatened by including only papers written in English, as all the search terms were defined in this language. On the other hand, it is considered that the authors of an SMS may make errors of judgement when analysing the relevant publications. This is a horizontal rather than a vertical analysis [35], on which ground relevant publications may have been overlooked. Additionally, although the collection of terms used in the search string were the most commonly accepted by other authors, other terms used to describe relevant publications may have been overlooked. Finally, the publications were evaluated and classified based on the judgement and experience of the authors, and other researchers may have evaluated the publications differently.

\section{Conclusions and Future Work}

This paper describes the systematic mapping study conducted to answer the research question, what is the current state of the integration of agile processes and usability? We retrieved a total of 161 Primary Studies, published mainly in journals and conference proceedings.

According to the literature analyzed in the SMS, the integration of ASDP and UCD can be classified in integration by processes, practices, technology and team. In addition we have identified integrations that include a combination of these types of integration, being the most popular processes integration. However, we consider practices integration as the most appropriate for integration in ASDP because they do not involve far-reaching changes to ASDPs. We think that the culture that developers within an agile team requires a lot of effort to acquire, so adopting a new process that includes usability can be counterproductive. The adoption of usability techniques or practices is the most appropriate and it is the objective of our research to define the transformations of these techniques to adapt them to the agile discipline.

The agile community is very much interested in the adoption of usability techniques in its development process. None of the various adoption proposals that have been put forward to date makes formalized adaptations for adoption in agile developments. On this ground, there is a need for more research in this respect. Our line of future research aims precisely to identify how to improve the adoption of usability techniques in agile developments. This adoption process would involve technique adaptation and should account for both the philosophy of agile developments and the essence of usability techniques. Additionally, we will extend our literature survey to include other DBs like ScienceDirect, SpringerLink and Web of Science and we will apply snowballing to assure that the search is as comprehensive as possible.

\section{Acknowledgment}

This research was funded by the "Proyecto DIUDA 22316" and by the Spanish Ministry of Education, Culture and Sports FLEXOR and "Realizando Experimentos en la Industria del Software: Comprensión del Paso de Laboratorio a la Realidad" projects (TIN2014-52129-R and TIN2014-60490-P, respectively) and the eMadrid-CM "Investigación y Desarrollo de Tecnologías Educativas en la Comunidad de Madrid" project (S2013/ICE-2715).

\section{References}

[1] K. Beck, M. Beedle, A. van Bennekum, A. Cockburn, W. Cunningham, M. Fowler, J. Grenning, J. Highsmith, A. Hunt, R. Jeffries, J. Kern, B. Marick, R. C. Martin, S. Mellor, K. Schwaber, J. Sutherland, and D. Thomas. (2001). Manifesto for agile software development, [Online]. Available: http://www.agilemanifesto.org/ (visited on Jun. 2016).

[2] J. D. Gould and C. Lewis, "Designing for usability: Key principles and what designers think", Commun. acm, vol. 28, no. 3, pp. 300-311, 1985. DOI: 10.1145/3166.3170.

[3] K. Beck, "Embracing change with extreme programming", Computer, vol. 32, no. 10, pp. 70-77, 1999.

[4] M. Cohn, Succeeding with agile: Software development using scrum. Pearson Education, 2009. 
[5] M. Brhel, H. Meth, A. Maedche, and K. Werder, "Exploring principles of user-centered agile software development: A literature review", Information and software technology, vol. 61, pp. 163-181, 2015. DOI: $10.1016 / j$.infsof.2015.01.004.

[6] S. Humayoun, Y. Dubinsky, and T. Catarci, "A three-fold integration framework to incorporate user-centered design into agile software development", Lecture notes in computer science (including subseries lecture notes in artificial intelligence and lecture notes in bioinformatics), vol. 6776 LNCS, pp. 55-64, 2011. DOI: 10.1007/978-3-642-21753-1_7.

[7] D. Salah, R. Paige, and P. Cairns, "A systematic literature review for agile development processes and user centred design integration", in Acm international conference, 2014, pp. 5-14. DOI: 10.1145/ 2601248. 2601276.

[8] A. Wale-Kolade, P. Nielsen, and T. Päivärinta, "Integrating usability practices into agile development: A case study", in 23rd international conference on information systems development, 2014, pp. 337347 .

[9] D. Fox, J. Sillito, and F. Maurer, "Agile methods and user-centered design: How these two methodologies are being successfully integrated in industry", in Agile conference, 2008, pp. 63-72. DOI: 10.1109/Agile.2008.78.

[10] S. Butt, W. Ahmad, and L. Rahim, "Handling tradeoffs between agile and usability methods", in International conference on computer and information sciences, iccoins - a conference of world engineering, science and technology congress, estcon, 2014, pp. 1-6. DOI: 10.1109/ICCOINS.2014.6868450.

[11] J. Lee, D. McCrickard, and K. Stevens, "Examining the foundations of agile usability with extreme scenario-based design", in Agile conference, 2009, pp. 3-10. DOI: 10.1109/AGILE. 2009.30.

[12] L. Cao and B. Ramesh, "Agile requirements engineering practices: An empirical study", Ieee software, vol. 25 , no. 1 , pp. 60-67, 2008. DOI: 10.1109/MS.2008.1.

[13] S. Chamberlain, H. Sharp, and N. Maiden, "Towards a framework for integrating agile development and user-centred design", Lecture notes in computer science (including subseries lecture notes in artificial intelligence and lecture notes in bioinformatics), vol. 4044 LNCS, pp. 143-153, 2006.

[14] D. Kane, "Finding a place for discount usability engineering in agile development: Throwing down the gauntlet", in Agile development conference, 2003, pp. 40-46. DOI: 10.1109/ADC. 2003.1231451.

[15] O. Sohaib and K. Khan, "Integrating usability engineering and agile software development: A literature review", in International conference on computer design and applications, 2010, pp. V232-V238. DOI: 10.1109/ICCDA.2010.5540916.

[16] T. T. Hewett, R. Baecker, S. Card, T. Carey, J. Gasen, M. Mantei, G. Perlman, G. Strong, and W. Verplank, "Acm sigchi curricula for human-computer interaction", New York, NY, USA, Tech. Rep., 1992.

[17] J. Barksdale, E. Ragan, and D. McCrickard, "Easing team politics in agile usability: A concept mapping approach", in Agile conference, 2009, pp. 19-25. DOI: 10.1109/AGILE.2009.57.

[18] D. D. Brown, "Five agile ux myths", J. usability studies, vol. 8, no. 3, pp. 55-60, 2013.

[19] M. Seyam, "Enhancing usability through agility: Pair programming for a practice-oriented integration approach", in 2015 international conference on collaboration technologies and systems (cts), 2015, pp. 460-463. DOI: 10.1109/CTS.2015.7210467.

[20] A. Bertholdo, T. Da Silva, C. De O. Melo, F. Kon, and M. Silveira, "Agile usability patterns for ucd early stages", Lecture notes in computer science (including subseries lecture notes in artificial intelligence and lecture notes in bioinformatics), vol. 8517 LNCS, no. 1, pp. 33-44, 2014. DOI: 10. 1007/978-3-319-07668-3-4.

[21] K. Schwaber and M. Beedle, Agile software development with scrum. Prentice Hall, 2001.

[22] M. Poppendieck and T. Poppendieck, Lean software development: An agile toolkit: An agile toolkit. Addison-Wesley, 2003.

[23] D. F. Rico, "What is the roi of agile vs. traditional methods", Tickit international, vol. 10, no. 4, pp. $9-18,2008$.

[24] S. Adikari, C. McDonald, and J. Campbell, "Little design up-front: A design science approach to integrating usability into agile requirements engineering", Lecture notes in computer science (including subseries lecture notes in artificial intelligence and lecture notes in bioinformatics), vol. 5610 LNCS, no. 1, pp. 549-558, 2009. DOI: 10.1007/978-3-642-02574-7_62.

[25] H. Beyer, User-centered agile methods. Morgan \& Claypool, 2010. DOI: 10. 2200/S00286ED1V01Y201002HCI010.

[26] R. Bonacin, M. Baranauskas, and M. Rodrigues, "An agile process model for inclusive software development", Lecture notes in business information processing, vol. 24 LNBIP, pp. 807-818, 2009. DOI: 10.1007/978-3-642-01347-8_67.

[27] A. Costa, L. Reis, and M. Loureiro, "Hybrid user centered development methodology: An application to educational software development", Lecture notes in computer science (including subseries lecture 
notes in artificial intelligence and lecture notes in bioinformatics), vol. 8699, pp. 243-253, 2014. DOI: 10.1007/978-3-319-13296-9_27.

[28] C. Felker, R. Slamova, and J. Davis, "Integrating ux with scrum in an undergraduate software development project", in 43rd acm technical symposium on computer science education, 2012, pp. 301-306. DOI: $10.1145 / 2157136.2157226$.

[29] L. Liikkanen, H. Kilpiö, L. Svan, and M. Hiltunen, "Lean ux - the next generation of user-centered agile development?", in The 8th nordic conference on human-computer interaction: Fun, fast, foundational, 2014, pp. 1095-1100. DOI: 10.1145/2639189.2670285.

[30] T. Memmel, F. Gundelsweiler, and H. Reiterer, "Cruiser: A cross-discipline user interface and software engineering lifecycle", Lecture notes in computer science (including subseries lecture notes in artificial intelligence and lecture notes in bioinformatics), vol. 4550 LNCS, no. 1, pp. 174-183, 2007.

[31] Z. Hussain, W. Slany, and A. Holzinger, "Investigating agile user-centered design in practice: A grounded theory perspective", Lecture notes in computer science (including subseries lecture notes in artificial intelligence and lecture notes in bioinformatics), vol. 5889 LNCS, pp. 279-289, 2009. DOI: 10.1007/978-3-642-10308-7_19.

[32] Z. Hussain, W. Slany, and A. Holzinger, "Current state of agile user-centered design: A survey", Lecture notes in computer science (including subseries lecture notes in artificial intelligence and lecture notes in bioinformatics), vol. 5889 LNCS, pp. 416-427, 2009. DOI: 10.1007/978-3-642-10308-7_30.

[33] A. Kushniruk and E. Borycki, "Integrating low-cost rapid usability testing into agile system development of healthcare it: A methodological perspective", in Studies in health technology and informatics, vol. 210, 2015, pp. 200-204. DOI: 10.3233/978-1-61499-512-8-200.

[34] B. Losada, M. Urretavizcaya, J.-M. López, and I. Fernández-Castro, "Applying usability engineering in intermod agile development methodology. a case study in a mobile application", Journal of universal computer science, vol. 19, no. 8, pp. 1046-1065, 2013.

[35] K. Petersen, R. Feldt, S. Mujtaba, and M. Mattsson, "Systematic mapping studies in software engineering", in 12th international conference on evaluation and assessment in software engineering, 2008, pp. $71-80$.

[36] T. Da Silva, A. Martin, F. Maurer, and M. Silveira, "User-centered design and agile methods: A systematic review", in Agile conference, 2011, pp. 77-86. DOI: 10.1109/AGILE. 2011.24.

[37] A. Fernandez, E. Insfran, and S. Abrahão, "Usability evaluation methods for the web: A systematic mapping study", Information and software technology, vol. 53, no. 8, pp. 789-817, 2011. DOI: https: //doi.org/10.1016/j.inf sof .2011.02.007.

[38] Y. I. Ormeño and J. I. Panach, "Mapping study about usability requirements elicitation", in Advanced information systems engineering: 25th international conference, caise 2013, valencia, spain, june 1721, 2013. proceedings, C. Salinesi, M. C. Norrie, and Ó. Pastor, Eds. Berlin, Heidelberg: Springer Berlin Heidelberg, 2013, pp. 672-687. DOI: 10.1007/978-3-642-38709-8_43.

[39] T. Da Silva, M. Silveira, and F. Maurer, "Usability evaluation practices within agile development", in Annual hawaii international conference on system sciences, 2015, pp. 5133-5142. DOI: 10.1109/ HICSS. 2015.607.

[40] S. Luján-Mora and F. Masri, "Integration of web accessibility into agile methods", in 14th international conference on enterprise information systems, vol. 3 HCI, 2012, pp. 123-127.

[41] D. McCrickard, M. Sampat, and J. Lee, Building applications to establish location awareness: New approaches to design, implementation, and evaluation of mobile and ubiquitous interfaces. IGI Global, 2008, pp. 253-265. DOI: 10.4018/978-1-59904-693-8.ch016.

[42] S. Kieffer, C. Swine, and B. Macq, "Do i have to press the big button labelled spacebar to separate two words?", in International conference interfaces and human computer interaction, international conference game and entertainment technologies, 2012, pp. 81-88.

[43] T. Memmel, H. Reiterer, and A. Holzinger, "Agile methods and visual specification in software development: A chance to ensure universal access", Lecture notes in computer science (including subseries lecture notes in artificial intelligence and lecture notes in bioinformatics), vol. 4554 LNCS, no. 1, pp. 453-462, 2007.

[44] K. Abdelouhab, D. Idoughi, and C. Kolski, "Agile \& user centric soa based service design framework applied in disaster management", in 1st international conference on information and communication technologies for disaster management, 2014, pp. 1-8. DOI: 10.1109/ICT-DM.2014.6917792.

[45] J. Nosek, "Integrating software and usability engineering through jointly-constructed, event-based stories", in International workshop on interplay between usability evaluation and software development, i-used, vol. 407, 2008, pp. 47-49. 
[46] J. Patton, "Designing requirements: Incorporating usage-centered design into an agile sw development process", Lecture notes in computer science (including subseries lecture notes in artificial intelligence and lecture notes in bioinformatics), vol. 2418, pp. 1-12, 2002.

[47] J. Proulx and J. Robert, "To integrate a design-centered user approach to an agile software development approach", in 22nd conference francophone sur l'interaction homme-machine, 2010, pp. 125128.

[48] D. Salah, R. Paige, and P. Cairns, "Integrating agile development processes and user centred design a place for usability maturity models?", Lecture notes in computer science (including subseries lecture notes in artificial intelligence and lecture notes in bioinformatics), vol. 8742, pp. 108-125, 2014.

[49] J. Ungar and J. White, "Agile user centered design: Enter the design studio - a case study", in Conference on human factors in computing systems, 2008, pp. 2167-2177. DOI: 10.1145/1358628. 1358650.

[50] C. Lester, "Combining agile methods and user-centered design to create a unique user experience: An empirical inquiry", in 4th international conference on advances in computer-human interactions, 2011, pp. 16-21.

[51] L. Miller, "Case study of customer input for a successful product", in Agile conference, 2005, pp. 225234. DOI: 10.1109/ADC. 2005.16.

[52] V. Paelke and K. Nebe, "Integrating agile methods for mixed reality design space exploration", in Conference on designing interactive systems: Processes, practices, methods, and techniques, dis, 2008, pp. 240-249. DOI: 10.1145/1394445.1394471.

[53] D. Salah, R. Paige, and P. Cairns, "A practitioner perspective on integrating agile and user centred design", in 28th international bcs human computer interaction conference on hci - sand, sea and sky - holiday hci, Southport, UK: BCS, 2014, pp. 100-109. DOI: 10.14236/ewic/hci2014.11.

[54] W. Wan Ahmad, S. Butt, and L. Rahim, "Usability evaluation of the agile software process", Lecture notes in computer science (including subseries lecture notes in artificial intelligence and lecture notes in bioinformatics), vol. 8237 LNCS, pp. 640-651, 2013. DOI: 10.1007/978-3-319-02958-0_58.

[55] T. Øvad, "Agile user experience", in International conferences on interfaces and human computer interaction, game and entertainment technologies and computer graphics, visualization, computer vision and image, part of the multi conference on computer science and information systems, 2014, pp. 397-401.

[56] L. Constantine and L. Lockwood, "Usage-centered software engineering: An agile approach to integrating users, user interfaces, and usability into software engineering practice", in International conference on software engineering, 2003, pp. 746-747.

[57] M. McNeill, "Agile user-centred design", in Contemporary ergonomics, 2006, pp. 494-498.

[58] L. Schwartz, L. Vergnol, G. Gronier, A. Vagner, T. Altenburger, and S. Battisti, "How to reconcile agility and user-centered design in a development project?", in Acm international conference, 2009, pp. 337-340. DOI: 10.1145/1629826.1629881.

[59] L. Constantine and L. Lockwood, "Usage-centered engineering for web applications", Ieee distributed systems online, vol. 3, no. 3, pp. 42-50, 2002.

[60] S. Wilkes, "Some impacts of big data on usability practice", Commun. des. q. rev, vol. 13, no. 2, pp. 25-32, 2012. DOI: $10.1145 / 2424840.2424842$.

[61] S. Adikari, C. McDonald, and J. Campbell, "Agile user experience design: A design science enquiry", in 24th australasian conference on information systems, 2013, pp. 1-11.

[62] S. Butt, A. Onn, M. Butt, N. Inam, and S. Butt, "Incorporation of usability evaluation methods in agile software model", in 17th ieee international multi topic conference: Collaborative and sustainable development of technologies, 2014, pp. 193-199. DOI: 10.1109/INMIC. 2014.7097336.

[63] A. Costa, L. Reis, and M. Loureiro, "Lessons learned on developing educational systems using a hybrid user centered methodology", Advances in intelligent systems and computing, vol. 354, pp. 213-222, 2015. DOI: $10.1007 / 978-3-319-16528-8 \_20$.

[64] B. Losada, M. Urretavizcaya, and I. De Castro, "An integrated approach to develop interactive software", Lecture notes in computer science (including subseries lecture notes in artificial intelligence and lecture notes in bioinformatics), vol. 6949 LNCS, no. 4, pp. 470-474, 2011. DOI: 10.1007/9783-642-23768-3_60.

[65] B. Losada, M. Urretavizcaya, and I. Fernández-Castro, "A guide to agile development of interactive software with a user objectives driven methodology", Science of computer programming, vol. 78, no. 11, pp. 2268-2281, 2013. DOI: 10.1016/j.scico.2012.07.022.

[66] D. Salah, "A framework for the integration of user centered design and agile software development processes", in International conference on software engineering, 2011, pp. 1132-1133. DOI: 10.1145/ 1985793.1986017. 
[67] D. Salah, R. Paige, and P. Cairns, "Observations on utilising usability maturity model-human centredness scale in integrating agile development processes and user centred design", Communications in computer and information science, vol. 526, pp. 159-173, 2015. DOI: 10.1007/978-3-319-19860$6 \_13$.

[68] M. Singh, "U-scrum: An agile methodology for promoting usability", in Agile conference, 2008, pp. 555560. DOI: $10.1109 /$ Agile.2008.33.

[69] A. Abdallah, R. Hassan, and M. Azim, "Quantified extreme scenario based design approach", in Acm symposium on applied computing, 2013, pp. 1117-1122. DOI: 10.1145/2480362.2480572.

[70] A. Holzinger, M. Errath, G. Searle, B. Thurnher, and W. Slany, "From extreme programming and usability engineering to extreme usability in software engineering education $(\mathrm{xp}+\mathrm{ue}->\mathrm{xu})$ ", in International computer software and applications conference, 2005, pp. 169-172. DOI: 10.1109/COMPSAC. 2005.80.

[71] A. Peres, T. Da Silva, F. Silva, F. Soares, C. De Carvalho, and S. De Lemos Meira, "Agileux model: Towards a reference model on integrating ux in developing software using agile methodologies", in Agile conference, 2014, pp. 61-63. DOI: 10.1109/AGILE.2014.15.

[72] ISO. (2010). 9241-210:2010 - ergonomics of human-system interaction - part 210: Human-centred design for interactive systems, [Online]. Available: http://www.iso.org/ (visited on Jun. 2016).

[73] W. Hudson, "Adopting user-centered design within an agile process: A conversation", Cutter it journal, vol. 16 , no. 10 , pp. $5-12,2003$.

[74] T. Øvad and L. B. Larsen, "The prevalence of ux design in agile development processes in industry", in Agile conference, 2015, pp. 40-49. DOI: 10.1109/Agile.2015.13.

[75] Y. Jia, M. Larusdottir, and Å. Cajander, "The usage of usability techniques in scrum projects", Lecture notes in computer science (including subseries lecture notes in artificial intelligence and lecture notes in bioinformatics), vol. 7623 LNCS, pp. 331-341, 2012. DOI: 10.1007/978-3-642-34347-6_25.

[76] S. Ambler, "Bridging the gap", Dr. dobb's journal, vol. 31, no. 8, pp. 64-67, 2006.

[77] Z. Hussain, H. Milchrahm, S. Shahzad, W. Slany, M. Tscheligi, and P. Wolkerstorfer, "Integration of extreme programming and user-centered design: Lessons learned", Lecture notes in business information processing, vol. 31 LNBIP, pp. 174-179, 2009. DOI: 10.1007/978-3-642-01853-4_23.

[78] T. Illmensee and A. Muff, "5 users every friday: A case study in applied research", in Agile conference, 2009, pp. 404-409. DOI: 10.1109/AGILE. 2009.45.

[79] W. Rahim, W. Isa, A. Lokman, N. Taharim, and N. Wahid, "Engineering m-learning using agile user-centered design", in 8th international conference on next generation mobile applications, services and technologies, 2014, pp. 60-65. DOI: 10.1109/NGMAST.2014.46.

[80] W. Isa, A. Lokman, S. Aris, M. Aziz, J. Taslim, M. Manaf, and R. Sulaiman, "Engineering rural informatics using agile user centered design", in 2nd international conference on information and communication technology, 2014, pp. 367-372. DOI: 10.1109/ICoICT.2014.6914093.

[81] L. Caballero, A. Moreno, and A. Seffah, "Personas as a tool to involving human in agile methods: Contributions from hci and marketing", Lecture notes in computer science (including subseries lecture notes in artificial intelligence and lecture notes in bioinformatics) 5th ifip wg 13.2 international conference, hcse 2014, vol. 8742, pp. 283-290, 2014.

[82] A. Cajander, M. Larusdottir, and J. Gulliksen, "Existing but not explicit - the user perspective in scrum projects in practice", Lecture notes in computer science (including subseries lecture notes in artificial intelligence and lecture notes in bioinformatics), vol. 8119 LNCS, no. 3, pp. 762-779, 2013. DOI: $10.1007 / 978-3-642-40477-1 \_52$.

[83] D. Dayton and C. Barnum, "The impact of agile on user-centered design: Two surveys tell the story", Technical communication, vol. 56, no. 3, pp. 219-234, 2009.

[84] V. Grigoreanu and M. Mohanna, "Informal cognitive walkthrough (icw): Paring down and pairing up for an agile world", in Human factors in computing systems, 2013, pp. 3093-3096. DOI: 10.1145/ 2470654.2466421.

[85] M. Lárusdóttir, E. Bjarnadottir, and J. Gulliksen, "The focus on usability in testing practices in industry", Ifip advances in information and communication technology, vol. 332, pp. 98-109, 2010.

[86] M. Lárusdóttir, Å. Cajander, and J. Gulliksen, "Informal feedback rather than performance measurements - user-centred evaluation in scrum projects", Behaviour and information technology, vol. 33, no. 11 , pp. 1118-1135, 2014. DOI: 10.1080/0144929X.2013.857430.

[87] G. Meszaro and J. Aston, "Adding usability testing to an agile project", in Agile conference, 2006, pp. 289-294. DOI: 10.1109/AGILE. 2006.5.

[88] L. Nielsen and S. Madsen, "The usability expert's fear of agility - an empirical study of global trends and emerging practices", in 7th nordic conference on human-computer interaction, 2012, pp. 261-264. DOI: $10.1145 / 2399016.2399057$. 
[89] O. Sohaib and K. Khan, "Incorporating discount usability in extreme programming", International journal of software engineering and its applications, vol. 5, no. 1, pp. 51-62, 2011.

[90] P. Wolkerstorfer, M. Tscheligi, R. Sefelin, H. Milchrahm, Z. Hussain, M. Lechner, and S. Shahzad, "Probing an agile usability process", in Conference on human factors in computing systems, 2008, pp. 2151-2157. DOI: $10.1145 / 1358628.1358648$.

[91] D. J. Mayhew, The usability engineering lifecycle: A practitioner's handbook for user interface design. Morgan Kaufmann Publishers, 1999.

[92] H. Beyer, K. Holtzblatt, and L. Baker, "An agile customer-centered method: Rapid contextual design", Lecture notes in computer science (including subseries lecture notes in artificial intelligence and lecture notes in bioinformatics), vol. 3134, pp. 50-59, 2004.

[93] M. Budwig, S. Jeong, and K. Kelkar, "When user experience met agile: A case study", in Conference on human factors in computing systems, 2009, pp. 3075-3083. DOI: 10.1145/1520340.1520434.

[94] L. Plonka, H. Sharp, P. Gregory, and K. Taylor, "Ux design in agile: A dsdm case study", Lecture notes in business information processing, vol. 179 LNBIP, pp. 1-15, 2014. DOI: 10.1007/978-3-31906862-6.

[95] K. Kuusinen and T. Mikkonen, "Designing user experience for mobile apps: Long-term product owner perspective", in 20th asia-pacific software engineering conference (apsec), vol. 1, 2013, pp. 535-540. DOI: $10.1109 /$ APSEC .2013 .77$.

[96] T. Da Silva, M. Silveira, C. De O. Melo, and L. Parzianello, "Understanding the ux designer's role within agile teams", Lecture notes in computer science (including subseries lecture notes in artificial intelligence and lecture notes in bioinformatics), vol. 8012 LNCS, no. 1, pp. 599-609, 2013. DOI: 10.1007/978-3-642-39229-0_64.

[97] A. Ganci and B. Ribeiro, "Becoming a team player: The evolving role of design in the world of agile development", International journal of design management and professional practice, vol. 7 , no. 2, pp. 11-23, 2014.

[98] Z. Hussain, M. Lechner, H. Milchrahm, S. Shahzad, W. Slany, M. Umgeher, T. Vlk, C. K'offel, M. Tscheligi, and P. Wolkerstorfer, "Practical usability in xp software development processes", in 5th international conference on advances in computer-human interactions, 2012, pp. 208-217.

[99] M. Lievesley and J. Yee, "The role of the interaction designer in an agile software development process", in Conference on human factors in computing systems, 2006, pp. 1025-1030. DOI: 10.1145/ 1125451.1125647.

[100] T. Øvad and L. Larsen, "Experiences from training agile software developers in focused workshops", in International conferences on interfaces and human computer interaction, game and entertainment technologies and computer graphics, visualization, computer vision and image, part of the multi conference on computer science and information systems, 2014, pp. 355-359.

[101] M. Isomursu, A. Sirotkin, P. Voltti, and M. Halonen, "User experience design goes agile in lean transformation - a case study", in Agile conference, 2012, pp. 1-10. DOI: 10.1109/Agile.2012.10.

[102] K. Kuusinen, "Improving ux work in scrum development: A three-year follow-up study in a company", Lecture notes in computer science (including subseries lecture notes in artificial intelligence and lecture notes in bioinformatics), vol. 8742, pp. 259-266, 2014.

[103] J. Kollmann, H. Sharp, and A. Blandford, "The importance of identity and vision to user experience designers on agile projects", in Agile conference, 2009, pp. 11-18. DOI: 10.1109/AGILE. 2009.58.

[104] J. Brown, G. Lindgaard, and R. Biddle, "Stories, sketches, and lists: Developers and interaction designers interacting through artefacts", in Agile conference, 2008, pp. 39-50. DOI: 10.1109/Agile. 2008.54.

[105] J. Ferreira, J. Noble, and R. Biddle, "Interaction designers on extreme programming teams: Two case studies from the real world", in 5th new zealand computer science research student conference, 2007, pp. 1-8.

[106] J. Ferreira, H. Sharp, and H. Robinson, "User experience design and agile development: Managing cooperation through articulation work", Software - practice and experience, vol. 41, no. 9, pp. 963-974, 2011. DOI: $10.1002 /$ spe. 1012.

[107] T. Silva da Silva, M. Selbach Silveira, and F. Maurer, "Ten lessons learned from integrating interaction design and agile development", in Agile conference, 2013, pp. 42-49. DOI: 10.1109/AGILE. 2013.11.

[108] K. Tzanidou and J. Ferreira, "Design and development in the "agile room": Trialing scrum at a digital agency", Lecture notes in business information processing, vol. 48 LNBIP, pp. 372-378, 2010. DOI: 10.1007/978-3-642-13054-0_40.

[109] K. Kuusinen, T. Mikkonen, and S. Pakarinen, "Agile user experience development in a large software organization: Good expertise but limited impact", Lecture notes in computer science (including 
subseries lecture notes in artificial intelligence and lecture notes in bioinformatics), vol. 7623 LNCS, pp. 94-111, 2012. DOI: 10.1007/978-3-642-34347-6_6.

[110] A. Wale-Kolade, "Integrating usability work into a large inter-organisational agile development project: Tactics developed by usability designers", Journal of systems and software, vol. 100, pp. 54-66, 2015. DOI: $10.1016 / j \cdot j$.js. 2014.10 .036 .

[111] A. Martin, J. Noble, and R. Biddle, "Experience on the human side of agile", Lecture notes in business information processing, vol. 9 LNBIP, pp. 234-235, 2008.

[112] J. Lee, "Embracing agile development of usable software systems", in Conference on human factors in computing systems, 2006, pp. 1767-1770. DOI: 10.1145/1125451.1125784.

[113] J. K. Blomkvist, J. Persson, and J. Åberg, "Communication through boundary objects in distributed agile teams", in 33rd annual acm conference on human factors in computing systems, New York, NY, USA: ACM, 2015, pp. 1875-1884. DOI: 10.1145/2702123.2702366.

[114] J. Ferreira, H. Sharp, and H. Robinson, "Agile development and user experience design integration as an ongoing achievement in practice", in Agile conference, 2012, pp. 11-20. DOI: 10.1109/Agile. 2012.33.

[115] S. Humayoun, Y. Dubinsky, T. Catarci, E. Nazarov, and A. Israel, "A model-based approach to ongoing product evaluation", in Workshop on advanced visual interfaces avi, 2012, pp. 596-603. DOI: 10.1145/2254556.2254666.

[116] J. Hakim, T. Spitzer, and J. Armitage, "Sprint: Agile specifications in shockwave and flash", in Conference on designing for user experiences, 2003, pp. 1-14. DOI: 10.1145/997078.997111.

[117] A. Shankar, H. Lin, H.-F. Brown, and C. Rice, "Rapid usability assessment of an enterprise application in an agile environment with cogtool", in 33rd annual acm conference extended abstracts on human factors in computing systems, New York, NY, USA: ACM, 2015, pp. 719-726. DOI: 10.1145/2702613. 2702960.

[118] C. Peixoto and A. Da Silva, "A conceptual knowledge base representation for agile design of humancomputer interface", in 3rd international symposium on intelligent information technology application, vol. 1, 2009, pp. 156-160. DOI: 10.1109/IITA.2009.393.

[119] J. Gonçalves and C. Santos, "Polvo - software for prototyping of low-fidelity interfaces in agile development", Lecture notes in computer science (including subseries lecture notes in artificial intelligence and lecture notes in bioinformatics), vol. 6761 LNCS, no. 1, pp. 63-71, 2011. DOI: 10.1007/978-3642-21602-2_7.

[120] M. Najafi and L. Toyoshiba, "Two case studies of user experience design and agile development", in Agile conference, 2008, pp. 531-536. DOI: 10.1109/Agile.2008.67.

[121] T. Memmel, F. Gundelsweiler, and H. Reiterer, "Prototyping corporate user interfaces - towards a visual specification of interactive systems", in 2nd iasted international conference on human-computer interaction, 2007, pp. 177-182. 